Financial Markets, Institutions and Risks, Volume 3, Issue 1, 2019

ISSN (online) - 2521-1242 ISSN (print) - 2521-1250

\title{
Impacts of Stock Market Performance on Firms' Growth: With Reference to South Africa
}

http://doi.org/10.21272/fmir.3(1).50-62.2019

Weldeslassie Hailai Abera

PhD Research Fellow, University of KwaZulu-Natal, South Africa

Salecia Gouder

Associate Consultant at PricewaterhouseCoopers, South Africa

Muhummed Sheik

University of KwaZulu-Natal, South Africa

Ruel Booth

University of KwaZulu-Natal, South Africa

\begin{abstract}
Multiple of factors such as technological innovation, public policy and market landscape, the nature of competitions, firms (cost) structures, firms' strategies, stock market performances managerial skills and other indigenous and exogenous factors have an explicit and implicit influence on firm's growth. A wealth of literature indicates that there is a divergence of thoughts on the direction and the extent of these various factors on firms' growth. There is a divergence of views on whether the relative impacts of stocks market performance on firms' growth could be identified, and what are the best practices to capture such lines of thoughts? And hence disentangling the impact of stock market performance on firms' growth is particularly open-ended and disputable.
\end{abstract}

With this context, the key purpose of this article is to examine the impact of stock market performance on firm's growth in order to address the pillar questions raised above by considering the South African stock market as a case study. The data utilized for this study includes quarterly observations ranging from 2001Q1 to 2015Q4. Time series methods are applied with the purpose of empirically testing the impact of stock market performance on firms' growth. The empirical testing process involves Johansen's co-integration technique which is employed in order to establish the co-integrating nature of the relationship between the two previously mentioned variables. In addition, a Vector Error Correction Model (VECM) is utilized to ascertain the long-run dynamics of the link between the two variables. The evidence obtained from the empirical testing for a sample of sixty observations suggests that the performance of stock markets have a significant long-run impact on firms' growth.

The insightful results we obtained using the parsimonious methods reinforce and significantly support the view that stock market performances have a substantial impact on firms' growth in the long run.

Keywords: Stock market performance, firms' growth, Vector Error Correction Model.

JEL Classification: G00, G3, G32, L2, L25, L29.

Cite as: Weldeslassie H., Gouder S., Sheik M., Booth R. (2019). Impacts of Stock Market Performance on Firms' Growth: With Reference to South Africa. Financial Markets, Institutions and Risks, 3(1), 50-62. http://doi.org/10.21272/fmir.3(1).50-62.2019

(C) The Authors, 2019. This article is published with open access at Sumy State University.

\section{Introduction}

Recently, there has been an increased importance placed on the possibility of firms' growth being impacted by its link to stock market performance. In this context, the association between stock market development and economic growth has been studied by many researchers (Adjasi and Biekpe, 2006), (Cooray, 2010), (Enisan and Olufisayo, 2009), (Levine and Zervos, 1996). Although a few studies have been conducted to measure the impact of stock market performance on firms' growth, there are more studies which have been carried out in several countries that tend to focus on stock market development (Yartey, 2008) rather than on stock market performance. This raises the question of whether the erratic fluctuations in the performance of stock markets, in fact, have the power to enhance firms' growth or hamper it. Given the volatility of capital markets and the inherent need to continually increase firms' growth, it is indeed imperative to investigate any 
link between the two variables. The South African private sectors' reduced business confidence, given electricity supply constraints, has hindered their ability to finance profitable investment opportunities for growth (National Treasury, 2015). Hence, this research seeks to ascertain whether a relationship, in fact, exists between the performance stock markets and firms' growth. The results of which, would provide firms with the necessary knowledge of obtaining finance through capital markets.

Several studies utilize time series Ordinary Least Squares regression analyses to ascertain the impacts of stock markets on economic growth (Chipaumire and Ngirande, 2014), (Oluwatosin, Taiwo, and Yusuf, 2013) and have found scepticism in the robustness of the results due to small sample sizes. That is, the explanatory power of the model is considerably weaker for small samples. Therefore, there are econometric advantages associated with analysing the relationship shared between growth and stock market performance, using time series models that can address the issues of endogeneity as well as causality. Thus, this paper utilizes a time series model to examine the impacts of stock market performance on firms' growth. Predictably, time series models have their own drawbacks. Precisely, the need for data ranging longer time spans narrows the focus of this study down to the All Share Index of the Johannesburg Stock Exchange. Even though the absence of other indices from the sample does not allow inferences to be made for specific sectors, the findings from utilizing the All Share Index have implications for South Africa in general. Furthermore, an understanding of how stock market performance has an impact on firms' growth could assist policymakers in South Africa and developing countries alike.

The research is structured as follows: the research questions along with the objectives of the study are outlined. A review of both the conceptual and empirical literature relating to the study is carried out. A discussion of the data and methods utilized in the study, as well as the results, are to follow. Lastly, the implications and limitations of the study are discussed.

\section{Research Questions and Objectives}

The goal of the research is to identify and evaluate the impact of stock market performance on the growth of South African listed firms.

\section{Objective:}

This study aims to observe the impact of stock market performance on firms' growth based on evidence from the South African economy.

\section{$\underline{\text { Research Questions }}$}

1. Is there any link between stock market performance and firms' growth?

2. Do the measures of stock market performance belong in the co-integrating relationship?

3. Do the determinants of firms' growth belong in the co-integrating relationship?

\section{Literature Review}

\section{Background}

Capital markets have been recognized for their contribution to economic growth since as early as 1911 (Schumpeter, 1912). The capital market serves as a platform for economic agents to raise finance. Government officials and private investors utilize these finances to expand operations and revolutionize infrastructure. Furthermore, capital markets allow the suppliers of capital to effortlessly restore their liquidity. Thus, the main purpose of the capital market is to allow for the efficient mobilization and distribution of a nation's funds. The vital functions of capital markets serve as a catalyst for the growth rate of a nation's economy.

The development of capital markets and the impact thereof on economic growth has extensively been studied in the financial literature (Demirgüç-Kunt and Levine, 1996), (Levine and Zervos, 1998), (Adjasi and Biekpe, 2006), (Enisan and Olufisayo, 2009). Numerous arguments highlight the vast importance of the relationship between the two variables (Caporale, Howells and Soliman, 2005), (Adjasi and Biepke, 2006), (Enisan and Olufisayo, 2009). Specifically, the inability to provide economic agents with the necessary capital for increasing productivity compromises an economy's growth potential. Thus, the capital market's allocative efficiency is crucial for the determination of an economy's growth and efficiency.

The ability of a capital market to improve performance is inherent in its development prospects. The capitalization and liquidity levels of stock markets are important determinants of performance. The dynamics 
Financial Markets, Institutions and Risks, Volume 3, Issue 1, 2019

ISSN (online) - 2521-1242 ISSN (print) - 2521-1250

of firm growth and the impact thereof on economic growth have been of interest in the literature. In general, economic theory advocates the notion that an increase in firm growth increases economic activity and in turn, raises growth.

Due to the highlighted aspects, many studies have focused on economic growth being impacted as a result of stock market dynamics. However, the varied beliefs suggest that a convergence of theories has not been reached over the years (Levine and Zervos, 1996), (Harris, 1997), (Arestis, Demetriades and Luintel, 2001), (Caporale, Howells and Soliman, 2005), (Chipaumire and Ngirande, 2014), (Jalloh, 2015). As Oluwatosin, Taiwo and Yusuf (2013) pointed out, differences in the development determinants of a nation's stock market can be used to explain the lack of convergence in the theory.

\section{Conceptual Framework}

\section{Determinants of Stock Market Performance}

Lane and Jacobsen (1995) assert that investors use current information to make trades which augments the performance of the stock market. Demirgüç-Kunt and Levine (1996) state that emerging economies have experienced an improvement in stock market performance, as greater interest is being placed on the issue by international investors through liberalization. On the contrary, De Santis and Imrohoroglu (1997) identified the extent to which a market is volatile, as measured by the level of market risk, to be a determinant of capital market performance. Volatility in emerging markets is found to be greater than that of developed markets, which translates into higher growth rates for emerging stock markets. Furthermore, liberalization in emerging markets enhances the performance of stock markets, although this leads to an increase in volatility. Similarly, Huang and Yang (1999) are in consensus with Demirgüç-Kunt and Levine (1996), and, De Santis and Imrohoroglu (1997) that liberalization in emerging markets increases volatility and stock market performance, due to the increase in foreign investment. This increase in volatility is because of changing economies that alter stock prices. Furthermore, liberalization encourages foreign investment, which allows for greater market participation and the expansion of markets. Levine and Zervos (1998) and Yartey (2008) state that the liquidity levels of stock markets are used as a determinant of stock market performance, where liquidity is calculated using turnover and value of stock traded ratios. In addition to identifying liquidity as a means for evaluating stock market performance, the market capitalization ratio is also used as a determinant of stock market performance. On the other hand, Madura (2007) identified interest rates as an economic factor that influences stock market performance. The risk-free interest rate is used as a benchmark to determine if an investor should purchase stocks that are priced to reflect high-expected returns above the risk-free interest rate. Furthermore, a significant number of stock market declines have occurred during periods of interest rate hikes. Bodie, Kane \& Marcus (2013) share the view of Madura (2007) that investor sentiment is an additional market-related factor that influences stock market performance. Specifically, investor expectations are reflected through stock valuations. With that said, stock market performance is not found to bear a high correlation with current economic conditions. Instead, positive investor sentiments may lead to rising stock prices even in weak economic conditions, due to optimistic expectations and vice versa. In contrast, Yartey (2008) and Bhana (2010) reached consensus in identifying transparency as a determinant of stock market performance, as increases in firms' transparency tend to increase stock trades. This view is analogous to the view held by Lane and Jacobsen (1995). Alternatively, Okonkwo and Ajudua (2014) assert that gauging capital market performance is heavily reliant on the level of market concentration. Consequently, illiquid capital markets are categorized by high levels of concentration, which reduces the benefits associated with diversification. A known measure of concentration is the average size of listed firms in a stock exchange.

\section{Determinants of Firm Growth}

Lane and Jacobsen (1995) found that firms' growth is enhanced through investments in brand extensions, which allows producing new products under existing brands. Brand extensions allow for increased revenues, positive brand images and greater firm value, thus providing the opportunity for greater revenues and firm growth. Similarly, Demirgüç-Kunt and Levine (1996) assert that increases in the performance of stock markets increase firm growth. This is achieved through higher debt-to-equity ratios, which allows firms to undertake investments in growth-enhancing projects. Furthermore, stock market liquidity encourages market participants to invest in firms that create value through investments in positive net present value projects. This increase in investments provides capital inflows which can be used to expand operations and enhance growth. Levine and Zervos (1998) found that countries with well-established financial institutions allow firms to grow more rapidly. Furthermore, the quality of external financing within these countries provides firms with greater opportunities for enhancing growth. Carrizosa (2007) identified revenue, added value and the value of assets 
Financial Markets, Institutions and Risks, Volume 3, Issue 1, 2019 ISSN (online) - 2521-1242 ISSN (print) - 2521-1250

as measures of firm growth. Revenues are indicative of quantities sold in the market. Added value measures the ability of the firm to enhance the value of output, though this information is not publicly available. An increase in the firm's assets is a useful measure of firm growth, though this metric is suggestive of changes in the firm's internal processes. By the same token, Zhou and De Wit (2009) define firm growth as the increase in sales, profit or employment of a firm between two time periods. Specifically, the degree of effectiveness by which the firm can organize, acquire and transform its resources (i.e. capital, labour and knowledge) into products and services determines the extent of firm growth. Similarly, Schimke and Brenner (2011) identified innovation as a determinant of firm growth. To be precise, increases in research and development (R\&D) induces higher growth since innovation and sales growth are mutually dependent.

\section{Empirical Studies}

The study by Levine and Zervos (1996) utilizes cross-country growth regressions which concludes that a significant link exists amongst developments in stock markets and growth. Moreover, the study made use of factors that determine stock market development which include metrics of size, risk diversification, and liquidity. In order to evaluate the link between stock market development and growth, an index comprising of stock market development metrics is regressed against per capita gross domestic product (GDP). Luintel and Khan (1999) in a study of ten countries utilized a Vector Autoregressive (VAR) classification and concluded that bi-directional causality exists between financial development and economic growth.

Like the study carried out by Luintel and Khan (1999), Ghirmay (2004) concluded that a long-run relationship exists between financial development and growth through the use of a sample containing thirteen countries in Sub-Saharan Africa and a VAR framework. Caporale, Howells, and Soliman (2005) equally show within a VAR framework that developments in stock markets impact on economic growth through investment productivity in the long-run. This study also tests the hypothesis that financial development causes growth, as suggested by endogenous growth models. The data includes quarterly observations of GDP, the value traded, and the market capitalization ratios from the year 1979 to 1988, for Malaysia, Philippines, Korea, and Chile. The findings are consistent with the empirical study carried out by Adjasi and Biepke (2006) in which the results indicate that capital markets significantly impact economic growth.

More recently, Enisan and Olufisayo (2009) show evidence supporting arguments postulated by Ghirmay (2004). After examining a sample of seven African countries, using data from 1980 - 2004, the study reveals that a causal association between the development in capital markets and economic growth is detected for all the countries in the sample.

Chipaumire and Ngirande (2014) used an OLS regression to observe the influence of South Africa's capital market on economic growth from $1995-2010$. However, the findings display that capital market liquidity affects economic growth in South Africa which opposes the argument postulated by Vacu (2013). In a study by Jalloh (2015) which investigates the way economic growth is affected by market capitalization, stock market development is found to be crucial to growth. More importantly, a $10 \%$ increase in market capitalization will result in a 5.4\% increase in economic growth for the sample of fifteen African countries.

In contrast, there are alternate views by researchers with regards to the role of capital markets in enhancing a country's growth potential. Harris (1997) within a cross-sectional framework concludes that capital markets and economic growth share a weak link in less developed countries. Similarly, Arestis, Demetriades, and Luintel (2001) utilize time series models for five developed economies covering the period 1968 - 1998, to demonstrate the association between economic growth and developments in capital markets. Several variables are used to explore the causal relationship shared between output and capital market development, these variables include the market capitalization ratio and GDP. The analysis is carried out under the Vector Autoregressive (VAR) framework, which is recognized for its innate ability to estimate the dynamics of the relationship between variables. The findings suggest that stock markets are a minor contributor to output growth. Furthermore, the volatility associated with capital markets has negative effects on output.

Osinubi (2002) in a study of the Nigerian economy using time series data extracted from 1980 - 2000 and a time series Ordinary Least Squares regression, concludes that positive links between economic growth and capital markets exist. However, it was identified that capital markets had a weak effect on economic growth. The findings reflect structural rigidities that are inherent in developing economies. The findings are in line with Harris (1997).

By the same token, a more recent study in which Vacu (2013) made use of data specific to South Africa, examined the long-term relationship between stock market performance and economic growth. The findings 
Financial Markets, Institutions and Risks, Volume 3, Issue 1, 2019

ISSN (online) - 2521-1242 ISSN (print) - 2521-1250

displayed evidence supporting the arguments advanced by Harris (1997) and Osinubi (2002). The study reveals that developing countries such as South Africa have experienced excessive growth, due to vast changes in the stock market and economy. Using time series quarterly data of various stock market and economic factors, for the period 1990Q1 - 2010Q4, together with Johansen's Co-integration framework, Granger Causality tests and a VECM, the author concludes that the relationship between the two variables was reasonably weak.

The convergence in views by a few empirical studies suggests that capital markets are positively related to growth. More specifically, stock markets are recognized for their' innate ability to enhance economic growth. However, it is worth mentioning that capital markets have an insignificant effect on economic growth in less developed economies. Thus, the divergence in views as suggested by the review of the literature is suggestive of rational justification for the contribution of this study to the literature.

\section{Methodology}

\section{Research Design}

The research for the dissertation is quantitative in nature, as opposed to being qualitative since it is based on the collection and examination of data in a numeric form. The purpose of the study is realized through statistical techniques, which allow for the sophisticated analysis of data. It follows that a research design as such is met by quantitative studies, rather than qualitative studies, which are structured in a narrative style.

\section{Sampling Techniques}

The population of firms that are available for observation includes all listed companies on the Johannesburg Stock Exchange. Thus, in order to avoid sampling error and biases, the Johannesburg Stock Exchange All Share Index (JALSH) is used as a measure of general performance of the South African capital market.

\section{Data and Sources}

Campbell and Perron (1991) argue that unit root hypothesis tests such as those implemented using Vector Autoregressive models have minimal dependence on the number of observations but are influenced rather, by the duration of the data. Furthermore, the authors contend that datasets containing fewer observations over a long-time span lead to tests with greater power than using data sets that are made up of more observations during a short period of time. Hence, the data is collected for a period of fifteen years (quarterly observations) due to availability (Luintel and Khan, 1999), (Ghirmay, 2004) from 2001 to 2015. The data is obtained from secondary sources and the main source for the collection of data is the Bloomberg terminal. The Bloomberg terminal is a computer system that is widely recognized for its real-time financial market data.

Following the literature, firm growth is measured by the sales figure that appears on the income statement for the Johannesburg Stock Exchange All Share Index (JALSH), which is a general representation of all firms listed on the index (Zhou and De Wit, 2009). Stock market performance is represented by the market capitalisation (MCAP) of the JALSH, index traded daily value or value of transactions (VTS) on the JALSH, and the number of listed shares on the JALSH (which is later dropped as there is no evidence of co-integration) (Oluwatosin, Taiwo and Yusuf, 2013).

\section{Econometric Methodology}

The Vector Autoregressive (VAR) model is employed in order to realise the first objective of analysing the association that exists between the performance of capital markets and firms' growth and consists of three variables (since the 'number of listed shares variable' is dropped), namely, firms' growth as measured by sales, the value of transactions, and market capitalisation. The VAR model is adopted since it is difficult to identify the dependent variable in the association that exists between the performance of capital markets and firms' growth. There is a probable chance of endogeneity amongst the variables, thus the use of the VAR model assists in identifying the endogenous nature of the variables. Furthermore, the VAR model identifies which variables display a causal relationship which is useful since a single dependent variable does not need to be identified prior to implementing the model. The studies carried out by Luintel and Khan (1999), Ghirmay (2004), and Caporale, Howells, and Soliman (2005) suggest that Johansen's Maximum Likelihood approach performs better than other estimators of long-run relationships do. Therefore, this method is followed on the grounds of a vector error correction representation of a VAR model with $\mathrm{p}$ lags which can be specified as:

To put long explanations short, the following expressions helps us to accomplish the research purpose and stated objectives above. 
Hamilton (1994) describes the four different cases to which the augmented Dickey-Fuller test has been applied. The null hypothesis is always that the variable has a unit root. They differ in whether the null hypothesis includes a drift term and whether the regression used to obtain the test statistic includes a constant term and time trend. Becketti (2013) provides additional examples showing how to conduct these tests.

The starting point of the model is assumed to be

$$
y_{t}=\alpha+y_{t-1}-\mu_{t}
$$

Where $\mu_{t}$ is an independently and identically distributed zero-mean error term? $\alpha=0$ which is $\alpha \neq 0$ a random walk without drift. We allow for a drift term by letting $\alpha$ be unrestricted

The Dickey-Fuller test involves fitting the model

$$
y_{t-1}=\alpha+\rho y_{t-1}+\sigma_{t}+\mu_{t-1}
$$

Note: Justify why we cannot employ the OLS approach! In other words,

Q. is the OLS approach inconsistent? Inefficient? Or both inconsistent and inefficient?

By subtracting equation (1) from (2)

If we repeated the same process repeatedly, we arrive at equation (3) where you started and designated it as equation (1)-I just asked you to include this part and to start from the true equation (1)

By the same token,

$$
\Delta y_{t}=\alpha+(\rho-1) y_{t-1}+\delta t+\gamma_{1} \Delta y_{t-1}+\gamma_{2} \Delta y_{t-2}+\ldots+\gamma_{k} y_{t-k}+\mu_{t-k}
$$

Finally, $\Delta y_{t}=\alpha+\rho y_{t-1}+\delta t+\gamma \sum_{t=1}^{k} \Delta y_{t-1}+\mu_{t}$

Notice: the recommendation is to start from equation (1) in lieu of starting from equation (3).

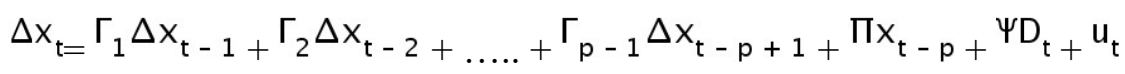

Where:

$\mathrm{X}=\mathbf{n} \times \mathbf{1}_{\text {vector of first order integrated variables }}$

$\Gamma_{1}, \Gamma_{2} \Gamma_{\mathbf{p}}=\mathbf{n} \times \mathbf{n}$ matrices of unknown parameters

$\mathrm{D}=\mathrm{a}$ set of stationary deterministic variables i.e. constant, trend and/or dummy variables

$\mathrm{u}=$ vector error term with zero mean and constant variance

(Arestis, Demetriades and Luintel, 2001)

The equilibrium properties of the equation are characterized by the rank $(\Pi)$ which is a square matrix of a size $^{n}$ where $n=3$. In the event of the presence of a co-integrating vector, it is implied that $\prod$ is rank deficient. The maximum eigenvalue and trace statistic are used to test the rank of $\Pi$ using appropriate critical values. It $\Pi$ is a rank of $\Gamma$ (where $\Gamma$ is greater than zero but less than $n)$ it can be decomposed into alpha $(n \times \Gamma$ ) and beta $(n \times \Gamma)$ matrices, such that: $\Pi=\alpha \beta^{\prime}$

The rows of the beta matrix are interpreted as distinct co-integrating vectors where form stationary processes. The alpha terms represent error correction coefficients which are indicative of the speed of adjustment toward the equilibrium point. Thus, substituting equation 2 into 1 gives:

$$
\nabla x_{t}=\Gamma_{1} \nabla x_{t-1}+\Gamma_{2} \nabla x_{t-2}+, \ldots \Gamma_{p-1} \nabla x_{t-p_{+1}}+\alpha\left(\beta^{\prime} x_{t-p}\right)+\psi D_{t}+u_{t} \ldots \ldots \ldots \ldots
$$

Final note:

Consider the parameters in various situations such as: Just for your consumption and understanding 
Financial Markets, Institutions and Risks, Volume 3, Issue 1, 2019

ISSN (online) - 2521-1242 ISSN (print) - 2521-1250

1. $\alpha \neq 0,|\rho|<1, \delta \neq 0$-the deterministic trend with drift and stationary AR (1) component I (0)

2. $\alpha \neq 0,|\rho|=1, \delta \neq 0$-random walk with drift and the deterministic trend

3. $\alpha \neq 0,|\rho|=1, \delta=0$ - random walk with drift

4. $\alpha \neq 0,|\rho|=0, \delta \neq 0$-the deterministic trend

5. $\alpha=0,|\rho|=1, \delta=0$ - a pure random walk

The above-mentioned specification is a basic test of long-run cause and effect which will determine the impact of stock market performance of a firm's growth. Once the co-integrating vector/s is identified, causality tests can be carried out. Granger causality tests can be performed on the output generated in the alpha matrix of the vector error correction model. Short-run causality between the variables is tested using the null hypothesis that lags of a variable $(x)$ do not Granger cause another variable $(y)$ against the alternative hypothesis that lags of a variable $(x)$ do Granger cause another variable $(y)$. Furthermore, the statistical significance of the output in the beta matrix is determined in order to analyze the dynamics of the long-run association between the variables.

The VECM is further utilized to realize the second and third objectives. These objectives are used to determine whether the measures of stock market performance and firm growth belong in the co-integrating equation. By imposing restrictions on the VECM, hypothesis tests are carried out to determine whether each measure of stock market performance and the measure of firm growth, in fact, belong in the co-integrating relationship. The null hypothesis of the variable $\beta(I, j)=0$ (the $\mathrm{j}^{\text {th }}$ coefficient in the $i^{\text {th }}$ co-integrating relationship of the beta matrix) is tested against the alternative hypothesis that $\beta(I, j) \neq 0$. The statistical significance of each variable as measured by the resultant $p$-value assists in determining if each variable can be used as a determinant of stock market performance or firm growth.

\section{Data Analysis}

The testing of the data is carried out using the EViews data analysis software, which allowed for the estimation of a Vector Error Correction model. EViews is a statistical software package that requires minimal knowledge of the structure of the programme and is known for its' user-friendliness, specifically when utilizing time series data. The use of standardized software packages is advisable when conducting research projects. Therefore, EViews was used for the analysis of data over other, more complicated packages such as SPSS and Stata 13.

\section{Empirical Results}

The analysis of the data commences with converting the data into natural logs - for interpretation purposes (Ndako, 2010). Thereafter, residual diagnostic tests for normality are carried out, followed by unit root testing of the variables. The next step is to ascertain the optimal lag length of the VAR Model, after which cointegration tests using Johansen's Maximum Likelihood procedure are performed. Thereafter, the long-run dynamics between stock market performance and firms' growth is studied by constructing a VECM. After which is a discussion of a graphical representation of the data using impulse response functions. Lastly, restrictions are imposed on the VECM to identify whether each measure of stock market performance and the measure of firms' growth belong in the co-integrating equation.

\section{Preliminary Analysis}

Residual diagnostic tests for normality are imperative in that assumptions of normality allow for inferences to be made for broader generalizations of the population. Thus, graphical methods (histogram), as well as formal tests (Jarque-Bera), are used to test for normality. The Jarque-Bera method examines the null hypothesis (H0) of a normal distribution against the alternative hypothesis (H1) of a non-normal distribution. The p-value related to the Jarque-Bera statistic is 0.745 which indicates that $\mathrm{H} 0$ cannot be rejected. Thus, it can be concluded that the residuals are normally distributed, and this is confirmed by the histogram below, which is bell-shaped. 


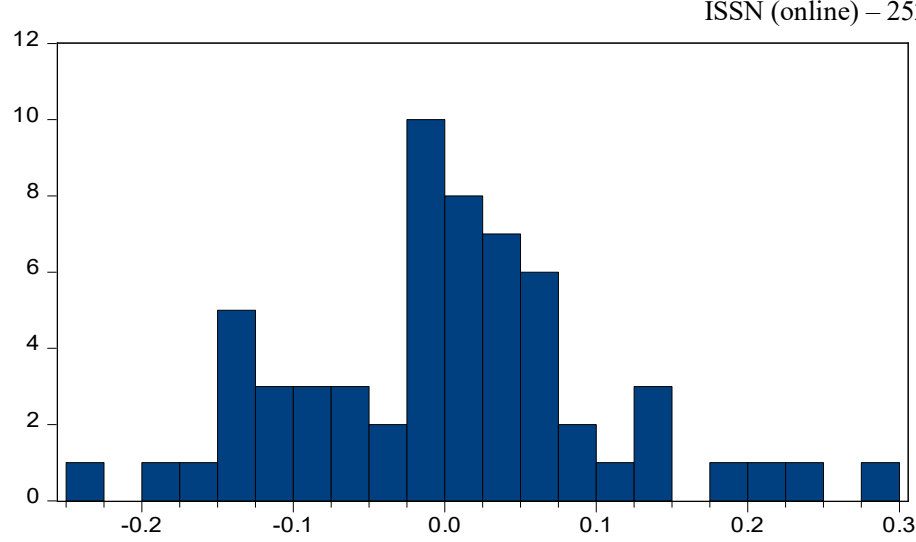

\begin{tabular}{lr}
\multicolumn{2}{l}{ Series: Residuals } \\
Sample 2001Q1 2015Q4 \\
\multicolumn{2}{l}{ Observations 60} \\
Mean & $-3.24 \mathrm{e}-15$ \\
Median & 0.007269 \\
Maximum & 0.282787 \\
Minimum & -0.249341 \\
Std. Dev. & 0.105776 \\
Skewness & 0.206342 \\
Kurtosis & 3.254506 \\
& \\
Jarque-Bera & 0.587704 \\
Probability & 0.745387 \\
\hline
\end{tabular}

Figure 1. Histogram and Descriptive Statistics

In order to analyze the presence of non-stationarity within each series, the order of integration for the variables is tested through unit root testing procedures. The Augmented Dickey-Fuller (ADF) test and the PhillipsPerron (PP) test are applied to the following series: market capitalization, the value of transactions, a few listed shares and sales. The results of both the ADF and PP tests show that all the series except the number of listed shares series are integrated of order one. To be precise, the series that are found to be integrated of order one is non-stationary in level form but are stationary in first differences. Thus, the null hypothesis of the presence of a unit root can be rejected for the market capitalization, value of transactions and sales series' in level form. According to econometric theory, if a series is non-stationary in level form, further testing is required to confirm that the series is stationary in first differences. The PP test is performed to confirm the results of the ADF test. The results of the ADF and PP tests are summarised in tables 1(a) and (b) on the next page:

Table 1(a). Unit root test: Augmented Dickey-Fuller test statistics ${ }^{1}$

\begin{tabular}{|c|c|c|c|c|}
\hline & Market Capitalisation & Value of Transactions & Number of Listed Shares & Sales \\
\hline Level form & -0.564323 & -2.206242 & $-4.390874 * * * 2$ & -1.155734 \\
\hline First Differences & $-6.322353 * * *$ & $-7.784234 * * *$ & N/A & $-12.93726^{* * *}$ \\
\hline \multicolumn{5}{|c|}{ Table 1(b) - Unit root test: Phillips-Perron test statistics3" } \\
\hline & Market Capitalisation & Value of Transactions & Number of Listed Shares & Sales \\
\hline Level form & -0.307858 & -2.272243 & $-12.82304 * * * 4$ & -1.402249 \\
\hline First Differences & $-6.283313 * * *$ & $-7.799568 * * *$ & N/A & $-12.26760 * * *$ \\
\hline
\end{tabular}

Source: Authors own estimation results.

To estimate a VAR model that is inclusive of the measures of stock market performance and firms' growth, the optimal lag length must be determined. The process of determining the optimal lag order involved estimating a VAR (2) model. After which, the Akaike (AIC), Schwarz (SC) and Hannan-Quinn (HQ) information criteria, along with the final prediction error (FPE) and likelihood ratio (LR) statistics are used to select the lag length of the VAR. The results of which are displayed in table 2 below.

Table 2. Selection of the VAR $(k)$ order

\begin{tabular}{|c|c|c|c|c|c|}
\hline Lag & LR $^{5}$ & FPE & AIC & SC & HQ \\
\hline 0 & NA & $1.17 \mathrm{e}-14$ & -23.56531 & $-23.45481^{*}$ & -23.52269 \\
\hline 1 & $28.90471^{* 6}$ & $9.17 \mathrm{e}-15^{*}$ & $-23.81007^{*}$ & -23.36807 & $-23.63961^{*}$ \\
\hline 2 & 10.25740 & $1.03 \mathrm{e}-14$ & -23.69498 & -22.92149 & -23.39667 \\
\hline
\end{tabular}

Source: Authors own estimation result.

The information criteria suggest that 1 lag is optimal except for the Schwarz information criterion. In this case, Akaike's information criterion is superior since the sample is relatively small (60 quarterly observations) and the choice of 1 lag is supported by the likelihood ratio and final prediction error statistics.

\footnotetext{
${ }^{1}$ Augmented Dickey-Fuller test with a constant in the test equation.

2 The asterisk *,**, and $* * *$ denotes $10 \%, 5 \%$, and $1 \%$ levels of significance respectively.

${ }^{3}$ Phillips-Perron test with a constant in the test equation.

${ }^{4}$ The asterisk $* * *$, and $* * *$ denotes $10 \%, 5 \%$, and $1 \%$ levels of significance respectively.

${ }^{5}$ Note: the acronyms LR, FPE, AIC, SC \& HQ refer to likelihood ratio, final prediction error, Akaike information criteria, Schwarz information criteria and Hannan-Quinn information criteria respectively.

${ }^{6}$ The asterisk * denotes the order of the VAR selected by the information criteria, as well as the FPE and LR statistics.
} 


\section{Inferential Statistics}

The study employed the use of Johansen's Maximum Likelihood framework to test for co-integration with the aim of examining the co-integrating association between the indicator of firms' growth and the indicators of stock market performance. The aim is to establish the presence of long-run relationships between the variables. The results of the co-integration test are presented in table 3 below.

Table 3. Johansen's Co-integration test

\begin{tabular}{|c|c|c|c|c|c|}
\hline $\mathrm{H}_{0}$ & $\mathrm{H}_{1}$ & Trace Statistic & $\begin{array}{c}\text { Critical Value }- \\
\mathrm{a}=0.05_{1}\end{array}$ & $\begin{array}{c}\text { Max-Eigen } \\
\text { Statistic }\end{array}$ & $\begin{array}{c}\text { Critical Value }- \\
\mathrm{a}=0.05_{2}\end{array}$ \\
\hline $\mathrm{r}=0$ & $\mathrm{r} \geq 1$ & $99.01009^{* * 3}$ & 29.79707 & $85.22833^{* *}$ & 21.13162 \\
\hline $\mathrm{r} \leq 1$ & $\mathrm{r} \geq 2$ & 13.78176 & 15.49471 & 13.38708 & 14.26460 \\
\hline
\end{tabular}

Source: Authors own estimation result.

The findings suggest that both the trace and maximum eigenvalue tests display evidence of one cointegrating

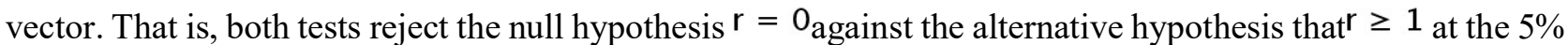
level of significance.

After the co-integrating rank has been established, the succeeding step is to estimate a VECM. The VECM is utilized to carry out causality tests and outline the long-run relationship between the variables. The results of which are displayed in tables 4(a) and (b) below.

The results of the beta matrix of the VECM display whether patterns of long-run relationships are evident within the system. The results are summarised in table 4(a) below.

Table 4(a). Long-run Relationship: Co-integrating Equation

\begin{tabular}{|c|c|c|c|}
\hline Variables & $\begin{array}{c}\text { Market Capitalisation - } \\
\Delta \operatorname{MCAP}_{(-1)}\end{array}$ & $\begin{array}{c}\text { Value of Transactions - } \\
\Delta \mathrm{VTS}_{(-1)}\end{array}$ & $\begin{array}{c}\text { Sales - } \\
\end{array}$ \\
\hline Coefficient & 1.331894 & -1.976952 & 1.000000 \\
\hline T-Statistic & $8.54067 * * * 4$ & $-12.9765^{* * *}$ & N/A \\
\hline
\end{tabular}

Source: Authors own estimation result.

In the long run, market capitalization has a significant and positive influence on sales whilst the value of transactions has a significant but negative influence on sales. This implies that an increase of $1 \%$ in market capitalization results in an increase of $1.33 \%$ in firms' growth as measured by sales. Similarly, an increase of $1 \%$ in the value of transactions leads to a decrease of $1.97 \%$ in firms' growth as measured by sales. Based on the results of the beta matrix, it can be concluded that the performance of stock markets has an impact on firms' growth in the long-run. The findings are like the studies carried out by (Ghirmay, 2004), (Caporale, Howells and Soliman, 2005), (Adjasi and Biepke, 2006), (Jalloh, 2015).

The alpha matrix of the Vector Error Correction Model (VECM) is used to test for short-run causality between the variables. The results are summarised in table 4(b) below.

Table 4(b). VECM Alpha Matrix: Causality Tests

\begin{tabular}{|c|c|c|c|}
\hline Variables & Market Capitalisation - & Value of Transactions - & Sales - \\
& $\Delta$ MCAP & $\Delta$ VTS & {$[-1.56143]$} \\
\hline$\Delta$ MCAP $^{\mathrm{t}-1}$ & {$[1.47060]$} & {$[-0.02697]$} & {$[-1.44368]$} \\
\hline$\Delta$ VTS $^{\mathrm{t}-1}$ & {$[-2.10708] * * 5$} & {$[1.20563]$} & {$[-3.66708] * * *$} \\
\hline$\Delta$ SALES $^{\mathrm{t}-1}$ & {$[-0.22301]$} & {$[-1.47179]$} & \\
\hline
\end{tabular}

Source: Authors own estimation result.

The findings show that the null hypothesis of non-causality cannot be rejected when firms' growth is dependent on the measures of stock market performance. Thus, there is no evidence of causal relationships in the short-run between stock market performance and firms' growth, when the level of market capitalization and value of transactions are viewed as channels through which stock markets affect firms' growth. However,

\footnotetext{
${ }^{1}$ Critical value corresponding to the trace statistic.

${ }^{2}$ Critical value corresponding to the maximum eigenvalue statistic

${ }^{3}$ The asterisk ** denotes one co-integrating equation at the $5 \%$ significance level.

4 The asterisk $* * *$, and $* * *$ denotes $10 \%, 5 \%$, and $1 \%$ levels of significance respectively.

5 The asterisk $*, * *$, and $* * *$ denotes $10 \%, 5 \%$, and $1 \%$ levels of significance respectively.
} 
the null hypothesis of non-causality can be rejected when market capitalization is dependent on the value of transactions. The results are like the study carried out by Vacu (2013).

The analysis of the VECM did not include an estimation of the amount of time required for the effects to occur. Thus, impulse response functions are used to display a graphical representation of the data. The impulse response function is displayed in Figure 1 on the following page.

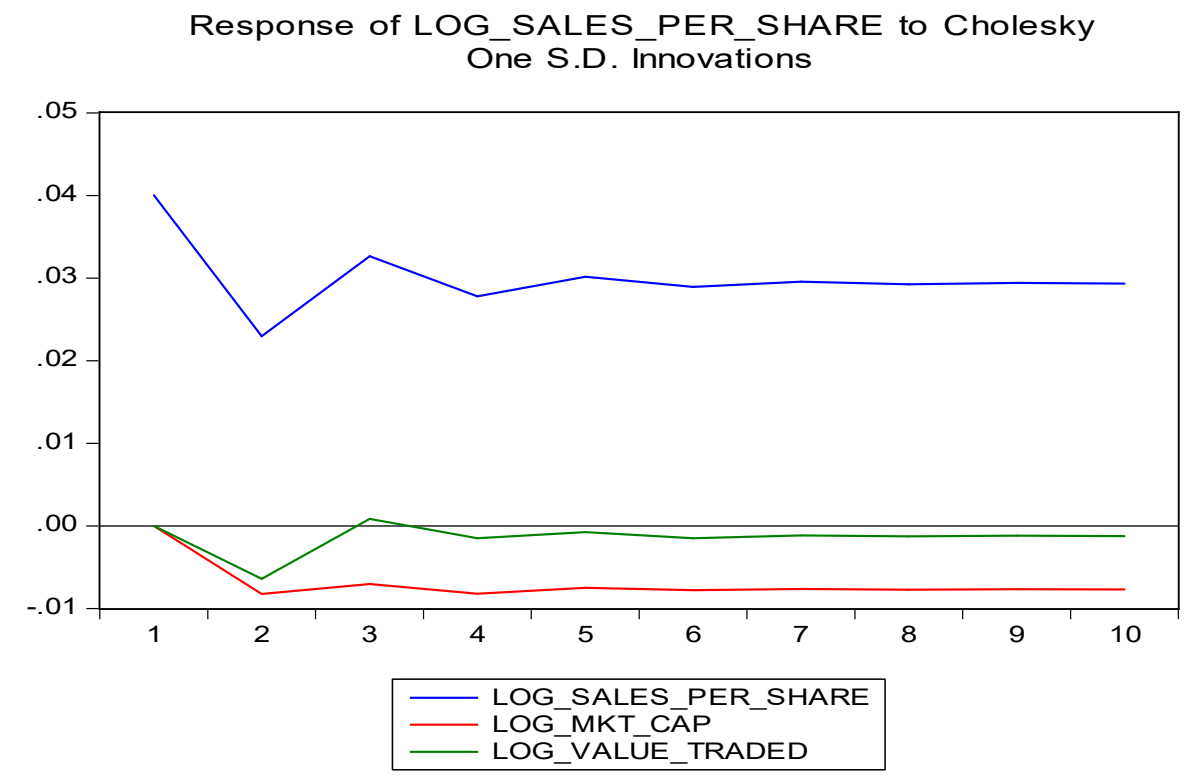

Figure 2. Impulse Response function of Sales per share

Source: Authors own data estimation results.

Impulse response functions display the receptiveness of a dependent variable to shocks of explanatory variables. The focus of the study is to gauge the impact of the measures of stock market performance on sales (a measure of firms' growth). Therefore, sales are the dependent variable of interest and only an analysis of the responses of sales to shocks in market capitalization and value of transactions is carried out. The results display that sales show no immediate response to shocks in both market capitalization and value traded. However, there is a negative response in the sales variable to shocks in both market capitalization and value traded by period two. From period three onwards, the response of sales to shocks in both variables begins to wear off which suggests stationarity in the variables.

Lastly, restrictions are imposed on the VECM in order to determine whether each measure of stock market performance and the measure of firm growth, in fact, belong in the co-integrating relationship $\left(2^{\text {nd }}\right.$ and $3^{\text {rd }}$ research questions). The results of the restriction tests are summarised in table 6 on the following page.

Table 5. Vector Error Correction Model Restrictions

\begin{tabular}{|c|c|c|c|}
\hline Variables & Market Capitalisation - & Value of Transactions - & Sales - \\
& $\Delta$ MCAP & $\Delta$ VTS & SALES \\
\hline Chi-Squared Statistic & 12.26951 & 70.81934 & 3.623959 \\
\hline Probability Value & $0.000460^{* * * 1}$ & $0.000000^{* * *}$ & $0.056953^{*}$ \\
\hline
\end{tabular}

Source: Authors own data estimation results.

The results show that all three variables are statistically significant and hence belong in the co-integrating relationship. The measures of stock market performance, i.e. market capitalization and value of transactions are significant at the $1 \%$ level of significance. Though, the measure of firms' growth, i.e. sales is significant at the $10 \%$ level of significance.

\section{Discussion of Findings}

\section{Summary}

The core objective of the study was to determine the impact of stock market performance on firms' growth within a South African context, using empirical methods. The study reviews the theory and empirical literature

1 The asterisk *,**, and *** denotes $10 \%, 5 \%$, and $1 \%$ levels of significance respectively. 
Financial Markets, Institutions and Risks, Volume 3, Issue 1, 2019

ISSN (online) - 2521-1242 ISSN (print) - 2521-1250

explaining the relationship between the variables. Most empirical studies have found that a link exists between stock market performance and growth in the long-run (Ghirmay, 2004), (Caporale, Howells and Soliman, 2005), (Adjasi and Biepke, 2006), (Jalloh, 2015). However, some studies argue that stock markets have an insignificant impact on growth in less developed economies (Harris, 1997), (Arestis, Demetriades and Luintel, 2001), (Osinubi, 2002).

Centred on both the empirical and theoretical literature surrounding the topic, the study detailed a time series empirical model that was used to explain the impacts of stock market performance on firms' growth (Ghirmay, 2004), (Caporale, Howells and Soliman, 2005), (Arestis, Demetriades and Luintel, 2001). The empirical model describes firms' growth as measured by sales, as a function of stock market performance measures (market capitalization, the value of transactions and the number of listed shares). Furthermore, the data were transformed into natural logs in order to normalize the data.

The stationarity of the variables was found to be an important aspect of macroeconomic analyses. Thus, the $\mathrm{ADF}$ and PP tests were used as formal tests for analysing the stationarity of the variables. Moreover, the study employed Johansen's co-integration technique in order to analyse the long-run impact of stock market performance on firms' growth, as well as a Vector Error Correction Model (VECM) to empirically examine the short-run and long-run dynamic relationship between the variables. In addition, the study employs graphical methods with impulse response functions.

\section{Conclusions}

The results of the Augmented Dickey-Fuller (ADF) and Phillips-Perron tests displayed that apart from the number of listed shares variable, all the other variables are stationary after first differencing. This led to the exclusion of the number of listed shares variable from the model since it is not possible for a meaningful longrun relationship to exist between variables that are integrated of different orders. The results of the Johansen Co-integration test showed that one co-integrating vector can be found as per the trace and maximumeigenvalue statistics. The existence of one co-integrating vector permitted the estimation of a VECM. The results largely indicate that stock market performance has an impact on firms' growth in the long-run. However, the same cannot be said for the short-run. The findings of this study are in accordance with the studies carried out by (Ghirmay, 2004), (Caporale, Howells and Soliman, 2005), (Adjasi and Biepke, 2006), and (Chipaumire and Ngirande, 2014).

\section{Implications of the Study}

Based on the quantitative findings of this research, the impacts of stock market performance on firms' growth present theoretical implications and recommendations for future research. The literature surrounding the topic has shown that a focus on accelerating stock market performance and development presents benefits, which when combined with increasing firms' growth can provide vast impacts on the economy. The findings of the research display that a focus on augmenting stock market performance will have an impact on firms' growth theoretically. Improved stock market performance could facilitate functionalities at the firm level, in terms of the financing of innovative projects as well as day-to-day operations. As a result, increased financial flexibility at the firm level allows the firm to sustain new demands following technological advancements, globalization, and/or increased market share. Furthermore, firms' growth bears a direct link with economy-wide growth which indirectly facilitates macroeconomic concerns such as the alleviation of poverty, upgraded infrastructure, skills development, and reduced unemployment, among other related issues.

\section{Limitations of the Study and Recommendations for Future Research}

This research was aimed at empirically deducing the impacts of stock market performance on firms' growth. Some of the limitations of this research as acknowledged by the authors include that the results of the study are restricted to listed firms on the Johannesburg Securities Exchange (JSE) since the sample of companies that make up the JSE All Share Index is made up of listed firms only. Thus, the ability to infer broader generalizations of all firms' in South Africa is hindered. Furthermore, data was not available for the measures used in the empirical model for years prior to 2001 which restricted the research to the use of sixty quarterly observations. These limitations, however, do not undermine the implications of the findings of this research. A review of the literature revealed that there is limited information available on the impacts of stock market performance on firms' growth, both theoretically and empirically. Thus, this study provides a foundation for future research that will allow for an understanding of the link between stock market performance and firms' growth. The channels through which each variable influences each other needs to be explored further in order to better understand the link between the variables. Furthermore, the extension of the empirical model to 
Financial Markets, Institutions and Risks, Volume 3, Issue 1, 2019 ISSN (online) - 2521-1242 ISSN (print) - 2521-1250

include alternate measures of stock market performance and firms' growth will assist in providing broader generalizations of all firms.

\section{References}

1. Adjasi, C. K. \& Biekpe, N. B. (2006). Stock market development and economic growth: The case of selected African countries. African Development Review, 18, 144-161.

2. Arestis, P., Demetriades, P. O. \& Luintel, K. B. (2001). Financial development and economic growth: the role of stock markets. Journal of Money, Credit and Banking, 33, 16-41.

3. Bhana, N. (2010). The stock market reaction to criticism of corporate governance practices of companies listed on the JSE. Investment Analysts Journal, 39, 1-12.

4. Bodie, Z., Kane, A. \& Marcus, A. (2012). Essentials of investments, McGraw-Hill Higher Education.

5. Campbell, J.Y. \& Perron, P. 1991. Pitfalls and opportunities: what macroeconomists should know about unit roots. In: Blanchard, O.J., Fisher, S._Eds.., NBER Macroeconomics Annual. MIT Press, Cambridge, MA.

6. Caporale, G. M., Howells, P. \& Soliman, A. M. (2005). Endogenous growth models and stock market development: evidence from four countries. Review of Development Economics, 9, 166-176.

7. Carrizosa, M.T. (2007). Firm growth, persistence, and multiplicity of equilibria: an analysis of Spanish manufacturing and service industries (Doctoral dissertation, Universitat Rovira I Virgili).

8. Chipaumire, G. \& Ngirande, H. (2014). How Stock Market Liquidity Impact Economic Growth in South Africa. Journal of Economics, 5, 185-192.

9. Cooray, A. (2010). Do stock markets lead to economic growth? Journal of Policy Modeling, 32, 448-460.

10. De Santis, G. (1997). Stock returns and volatility in emerging financial markets. Journal of international money and finance, 16, 561-579.

11. Demirgüç-Kunt, A. \& Levine, R. (1996). Stock markets, corporate finance, and economic growth: an overview. The World Bank Economic Review, 10, 223-239.

12. Enisan, A. A. \& Olufisayo, A. O. (2009). Stock market development and economic growth: Evidence from seven sub-Sahara African countries. Journal of Economics and Business, 61, 162-171.

13. Ghirmay, T. (2004). Financial Development and Economic Growth in Sub-Saharan African Countries: Evidence from Time Series Analysis. African Development Review, 16, 415-432.

14. Harris, R. D. (1997). Stock markets and development: A re-assessment. European Economic Review, 41, 139-146.

15. Huang, B.-N. \& Yang, C.-W. (2000). The impact of financial liberalization on stock price volatility in emerging markets. Journal of Comparative Economics, 28, 321-339.

16. Jalloh, M. 2015. Does Stock Market Capitalization Influences Economic Growth in Africa? Evidence from Panel Data. Applied Economics and Finance, 2(1), 91-101.

17. Lane, V. \& Jacobson, R. (1995). Stock market reactions to brand extension announcements: The effects of brand attitude and familiarity. The Journal of Marketing, 63-77.

18. Levine, R. \& Zervos, S. 1996. Stock market development and long-run growth. The World Bank Economic Review, 10, 323-339.

19. Levine, R. \& Zervos, S. (1998). Stock markets, banks, and economic growth. American economic review, 537-558.

20. Luintel, K. B. \& Khan, M. (1999). A quantitative reassessment of the finance-growth nexus: evidence from a multivariate VAR. Journal of development economics, 60, 381-405.

21. Madura, J. (2008). Financial institutions and markets, Cengage Learning EMEA.National Treasury. 2015. Economic Outlook. [Online]. Available at: http://www.treasury.gov.za/ documents $/$ national\% 20budget/2015/ review/chapter\%202.pdf [Accessed 23 February 2016].

22. Ndako, U. B. (2010). Stock markets, banks, and economic growth: time series evidence from South Africa. The African Finance Journal, 12, 72-92. 
ISSN (online) - 2521-1242 ISSN (print) - 2521-1250

23. Okonkwo, O. N. \& Ajudua, H. O. O. E. I. (2014). Stock Market Performance and Economic Growth in Nigeria: An Empirical Appraisal. European Journal of Business and Management, 6, 33-42.

24. Oluwatosin, E., Taiwo, A. \& Yusuf, S. (2013). Empirical Analysis of the Impact of Capital Market Efficiency on Economic Growth and Development in Nigeria. International Journal of Academic Research in Economics and Management Sciences, 2, 44-53.

25. Osinubi, T. S. (2002). Does the stock market promote economic growth in Nigeria?

26. Schimke, A. \& Brenner, T. (2011). Long-run factors of firm growth - a study of German firms.

27. Schumpeter, J. A. (1912). 1934, The Theory of Economic Development: An Inquiry into Profits, Capital, Credit, Interest and the Business Cycle. Trans. Redvers Opie. Cambridge, MA: Harvard University Press.

28. Vacu, N. P. (2013). The Impact of Stock Market Development on Economic Growth: Evidence from South Africa. (Masters dissertation, University of Fort Hare).

29. Yartey, C. A. (2008). The determinants of stock market development in emerging economies: is South Africa different? IMF Working Papers, 1-31.

30. Zhou, H. \& De Wit, G. (2009). Determinants and dimensions of firm growth. SCALES EIM Research Reports (H200903). 